\title{
Loss of Heterozygosity Associated with Uniparental Disomy in Breast Carcinoma
}

\author{
Sabita K. Murthy, Ph.D., Lisa M. DiFrancesco, M.D., R. Travis Ogilvie, M.D., \\ Douglas J. Demetrick, Ph.D., M.D. \\ Departments of Pathology and Laboratory Medicine (SKM, LMD, RTO, DJD), Oncology (LMD, RTO, DJD), \\ and Biochemistry and Molecular Biology (DJD), The University of Calgary; and Calgary Laboratory \\ Services (LMD, RTO, DJD), Calgary, Alberta, Canada
}

Loss of heterozygosity is commonly assumed to be due to deletion of the appropriate genomic region in one chromosome within a neoplastic cell but may be due to other mechanisms such as mitotic nondisjunction or somatic recombination leading to uniparental heterodisomy. We chose to study the genomic regions surrounding the $p 53$ and $R B 1$ tumor suppressor genes in breast carcinoma to evaluate the different mechanisms that could mediate loss of heterozygosity. A microsatellite analysis of polymorphic markers in $\mathbf{5 0}$ breast cancer samples showed loss of heterozygosity for at least 1 of the 10 markers analyzed in $\mathbf{5 0 \%}$ of the tumors studied, and an overall $8.47 \%$ of the informative loci showed loss of heterozygosity. All of the cases with loss of heterozygosity were further analyzed for gene copy number of the tumor suppressor genes $R B 1$ and $p 53$ by fluorescence in situ hybridization of either tumor touch preparations or microdissected tumor nuclei with specific genomic probes. Surprisingly, all samples showed the presence of both copies of tumor suppressor genes, including 4/50 cases showing loss of heterozygosity of tumor suppressor genespanning markers. One of the 4 cases showed loss of heterozygosity of markers spanning a distance of 6 cM over the $R B 1$ gene, with normal copy numbers of the gene. Three other cases showed loss of heterozygosity of markers within the tumor suppressor gene $(R B I$ or $p 53)$ and at least one other spanning marker. No cases showed a simultaneous reduction to homozygosity of markers both near the tumor suppressor gene and distal loci. We suggest that the

Copyright () 2002 by The United States and Canadian Academy of Pathology, Inc.

VOL. 15, NO. 12, P. 1241, 2002 Printed in the U.S.A.

Date of acceptance: July 20, 2002.

The Canadian Institutes of Health Research and Calgary Laboratory Services provided salary support to DJD. This work was supported by an Alberta Cancer Board Pilot Project grant.

Address reprint requests to: Douglas J. Demetrick, Ph.D., M.D., Room 302, HMRB, 3330 Hospital Dr. NW, Calgary, Alberta, Canada T2L 1X9; e-mail: demetric@ucalgary.ca; fax: 403-283-8727.

DOI: 10.1097/01.MP.0000032535.62750.D1 presence of both copies of the tumor suppressor gene in the cases with loss of heterozygosity of spanning markers and internal markers for that tumor suppressor gene could be explained by somatic recombination resulting in uniparental disomy, but not mitotic nondisjunction or deletion. As the mechanism for physical deletion of a chromosome may be different from those mediating somatic recombination, study of this phenomenon may identify different pathways of genomic instability that may be of diagnostic or treatment significance in breast or other cancers, particularly in those treatments based upon DNA-altering agents.

KEY WORDS: Breast cancer, FISH, Loss of heterozygosity, Microsatellite, Somatic recombination.

Mod Pathol 2002;15(12):1241-1250

The cumulative activation of oncogenes and inactivation of tumor suppressor genes causes disruption of critical events in cell division and differentiation, leading to neoplastic clones $(1,2)$. The paradigm of ordered alterations in the tumor suppressor gene is first a mutation of one allele and then the loss of the other allele, thus, allelic losses are regarded as hallmarks of chromosomal regions harboring tumor suppressor genes (1, 3-6). Reduction to homozygosity of the tumor suppressor gene can be detected as loss of heterozygosity of informative polymorphic markers in the region of the tumor suppressor gene. In conventional models of tumor suppressor gene inactivation, an initial mutational event sets the stage for cancer, however, it is the second event of mutation that is thought to initiate the cancer $(3,4)$.

By comparing the constitutional and tumor genotypes, it was possible to determine whether loss of heterozygosity occurred for the whole chromosome, or a part of the chromosome. As gene deletion is usually accepted to be the second hit, loss of heterozygosity at chromosomal sites of known tumor suppressor genes is considered indicative of 
mutations in the remaining copy of the gene and loss of tumor suppressor function of the gene product. The loss-of-heterozygosity event, however, may theoretically arise by several mechanisms, including deletion, mitotic nondisjunction, or somatic recombination resulting in uniparental disomy (Fig. 1; 7-12). The net result of any of these mechanisms may be loss of the normal allele of a tumor suppressor gene, with subsequent selection of clones bearing only mutant alleles. Using the typical example of a tumor suppressor gene, genetic analysis of retinoblastomas showed often that somatic recombination rather than deletion events resulted in the phenotypic expression of the mutated tumor suppressor gene $(10,13)$.

Uniparental disomy has been occasionally documented in pediatric cancers associated with inherited syndromes such as Beckwith-Wiedemann syndrome (14-16). In these pediatric tumors, uniparental disomy was confirmed using DNA from both parents. It is more difficult, however, to demonstrate uniparental disomy by conventional strategies in adult cancer types, such as breast cancer, where parental DNA samples are usually not available. Fortunately, many of these cases will have normal tissue within the specimen that can be dissected free of tumor and can serve as a source of normal patient DNA. From such specimens, indirect evidence for uniparental disomy may be gath- ered by comparing normal and neoplastic alleles of polymorphic markers surrounding or within a gene, with a quantitative evaluation of neoplastic cell gene copy number (Fig. 1). Although deletion of a gene may lead to a loss of heterozygosity pattern (Fig. 1: Options 2b, 2c, 3d), the presence of a normal gene copy number in the context of loss of heterozygosity is evidence for a different mechanism of allelic loss (Fig. 1: Options 2d, 3a, 3b, 3c, 3d). Surprisingly few of these evaluations have been performed. One study of breast cancer by fluorescence in situ hybridization (FISH) with an $R B 1$ genomic probe identified a discordance between FISHobserved $R B 1$ copy number and that expected from loss of heterozygosity analysis (17). These investigators suggested that somatic recombination or duplication of chromosome 13 containing mutant $R B 1$ could explain their findings. The authors also commented, however, that their evaluation of $p 53 \mathrm{did}$ not yield similar findings, and these observations were subsequently published (18). Another study of breast cancer examined loci within chromosome $3 p$ (19). This investigation found that the dominant alteration within $3 p$ in breast cancer was a physical deletion, demonstrated by concordance between loss of heterozygosity, as assessed by restriction fragment length polymorphisms, and FISH copy number. The other cases, however, showed discordance between FISH or loss of heterozygosity da-

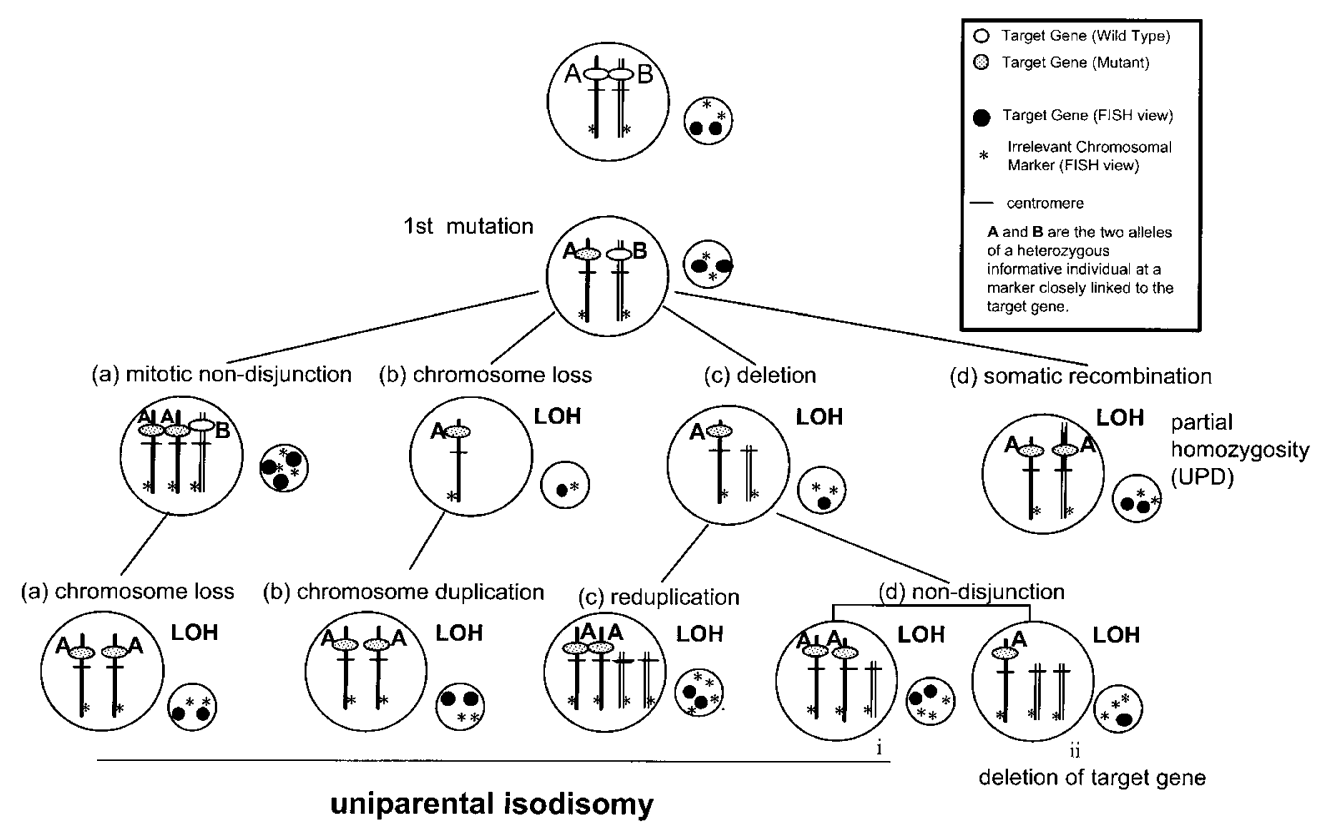

Mechanisms leading to Loss of Heterozygosity (LOH)

FIGURE 1. Mechanisms leading to loss of heterozygosity due to uniparental disomy. Strategies for possible recombination events leading to loss of heterozygosity and their detectable sequelae. Informative microsatellite alleles are A and B and are in the region of the tumor suppressor gene. White and grey markers distinguish specific alleles of the tumor suppressor gene. Solid black signals indicate the FISH interphase appearance with a specific tumor suppressor gene probe that cannot distinguish alleles. The asterisk $\left(^{*}\right)$ is a distal FISH chromosomal marker (or a centromeric probe). Note that several mechanisms can give rise to an loss of heterozygosity, but only $2 \mathrm{~b}, 2 \mathrm{c}$, and $3 \mathrm{di}$ and $3 \mathrm{dii}$ are associated with a copy number deletion. Cells with any of these events may be selected during clonal outgrowth. 
ta-either with normal copy number in the presence of loss of heterozygosity or allelic gain. The authors suggest that different mechanisms of tumor suppressor gene inactivation may be specific for certain chromosomal locations. Another study also identified discordance between FISH and loss of heterozygosity in specimens of Wilms' tumor (20) - a pediatric tumor that has been shown to illustrate uniparental disomy for the WT1 locus. In this study, 4/18 cases showed loss of heterozygosity with a normal copy number at DS16S422 by FISH. A recent, extensive study of colon carcinoma cell lines passaged in nude mice identified a variety of structural alterations over five chromosomes and also suggested a chromosome specific mode of mutational event (9). In those cases in which somatic recombination was the likely alteration, karyotypic analysis demonstrated gross structural lesions of varying complexity. Thus, studies of the mechanism of tumor suppressor gene inactivation, usually characterized by identification of mutations or deletions, have demonstrated that several mechanisms may occur and may be chromosome and/or tumor specific. Definition of the different mechanisms of tumor suppressor gene inactivation may identify different pathways of genomic instability among different tumors.

In our study, we have evaluated 50 breast carcinoma specimens using FISH and microsatellite analysis of two different tumor suppressor genes to identify potential mechanisms resulting in loss of heterozygosity around the two loci. The quantitative detection of loss of heterozygosity in tumor specimens was assisted by the preparation of pure populations of tumor cells either by touch preparations of tumor-rich specimens for FISH or by nuclear purification by laser capture microdissection (21) for FISH and microsatellite analysis.

\section{MATERIALS AND METHODS}

\section{Fresh-Frozen and Archival Tumor Specimens}

Fresh frozen or paraffin-embedded material from 50 primary breast carcinomas (1995-2000) were retrieved from the Research Tissue Repository of Calgary Laboratory Services. Serial $5-\mu \mathrm{m}$ sections were cut from the archival formalin-fixed, paraffinembedded tissues. All slides were stained with hematoxylin and eosin. The stained slides were used for morphologic characterization and for microdissection of both tumor and normal tissue.

\section{Microdissection and DNA extraction}

Pure specimens consisting of either tumor or normal tissue from archival paraffin-embedded tissues with $<80 \%$ tumor cellularity were prepared by laser capture microdissection (Pix Cell II, Arcturus Engineering Inc.). Cases with $>80 \%$ tumor cellularity were used without laser capture microdissection for tumor specimens, and their corresponding normal tissue margin blocks were used for normal tissue specimens. For the cases in which laser capture microdissection was performed, approximately 2000-5000 cells were collected on the laser capture microdissection cap. Normal cells were collected from the same slide on another cap or from a separate normal tissue section. DNA was extracted from cap samples by incubating the cells in $50 \mu \mathrm{L}$ of laser capture microdissection DNA digestion buffer (0.04\% proteinase $\mathrm{K} ; 10 \mathrm{Mm}$ Tris- $\mathrm{HCl}, \mathrm{pH} 8.0 ; 1 \mathrm{~mm}$ EDTA; and 1\% Tween-20-www.arctur.com) overnight at $37^{\circ}$ C. $2 \mu \mathrm{L}$ of this was directly used for the polymerase chain reaction (PCR).

\section{Polymorphic DNA Markers and Loss of Heterozygosity Analysis}

To evaluate loss of heterozygosity, the following 10 polymorphic markers distributed on chromosomes 13 and 17 were used: D13S260, D13S270, RBi2, D13S172, D13S274, D17S938, D17S796, p53 15.1, D17S786, and D17D795 (22) (Fig. 2A). The five markers on each chromosome were chosen such that at least one marker was within the tumor suppressor gene itself (RBi2 and p53-15.1) to confirm the presence or loss of the tumor suppressor gene; one marker at the distal end of the chromosome arm to identify deletion of the entire chromosome or chromosome arm (D13S274 and D17S795), and the other 3 markers spanning the tumor suppressor gene. For PCR amplification and detection, the forward primer of each primer set was labeled with Licor IRD ${ }^{700}$ fluorescent dye. The PCR reaction was set up as described (22) for the respective primer sets, and the amplified samples were run on a $6 \%$ sequencing gel and analyzed using GeneProfiler/ RFLPScan software (Scanalytics, Billerica MA). Signal intensities of polymorphic markers were quantitated and compared with those of normal tissue DNAs. A reduction in signal intensity of $>50 \%$ was considered as showing loss of heterozygosity (23). Microsatellite instability is defined as change of allelic length due to either insertion or deletion of repeat units in a microsatellite within a tumor sample, when compared with normal tissue (24).

\section{Gene Copy Number Analysis by Fluorescence In Situ Hybridization}

Copy number analysis of the tumor suppressor genes $p 53$ and $R B 1$ were evaluated by fluorescence in situ hybridization. A genomic probe for $R B 1$ was obtained from RZPD, Germany (ICRFc108F0473) and $p 53$ was obtained from the UK Human 

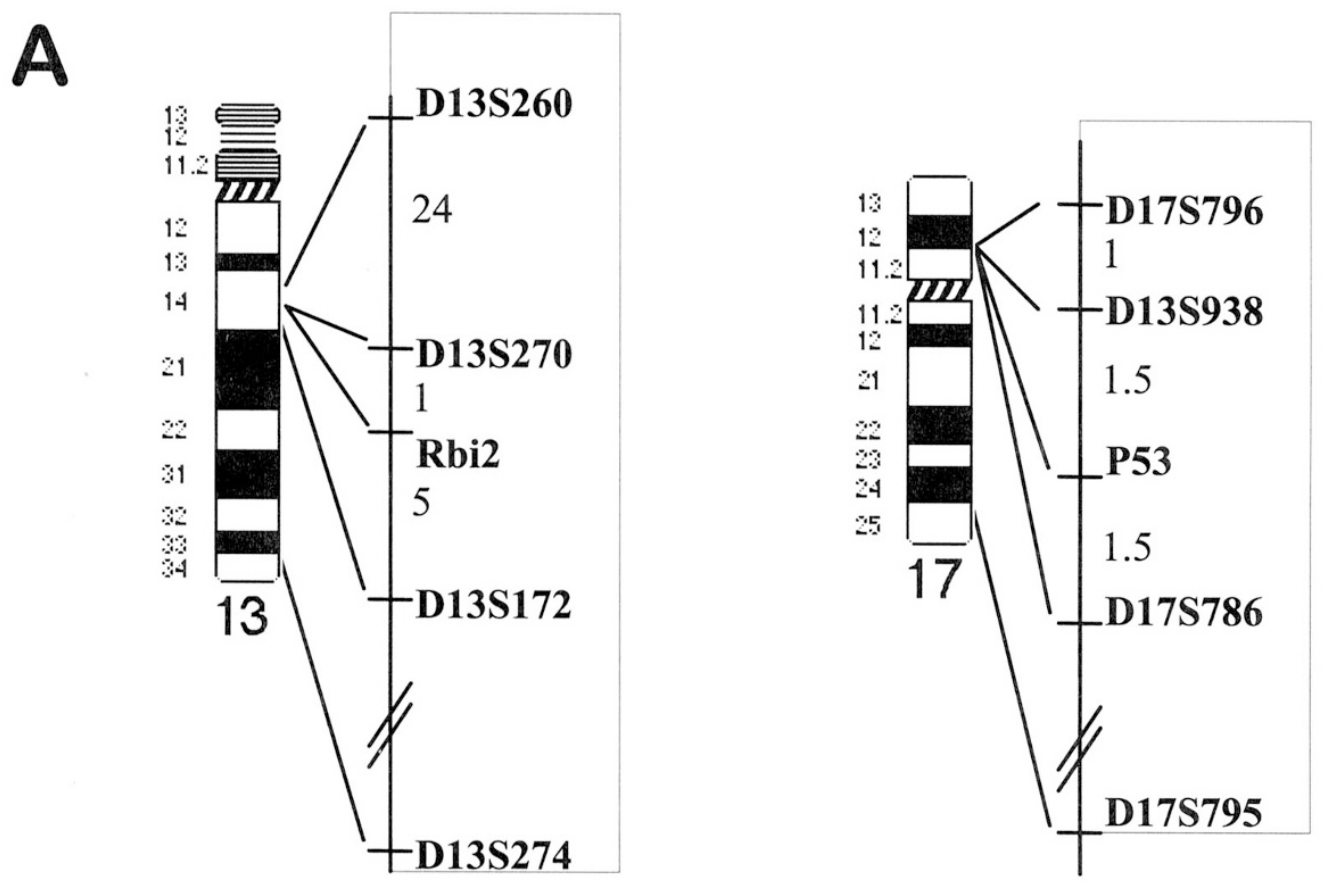

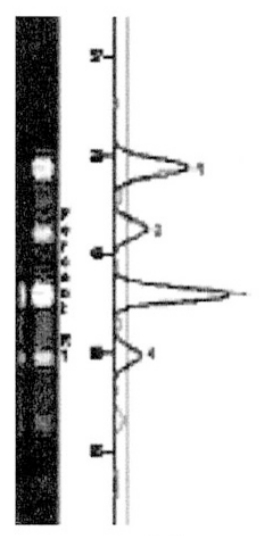

$\mathbf{N}$

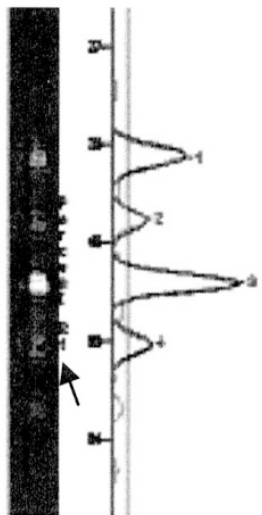

$\mathrm{T}$

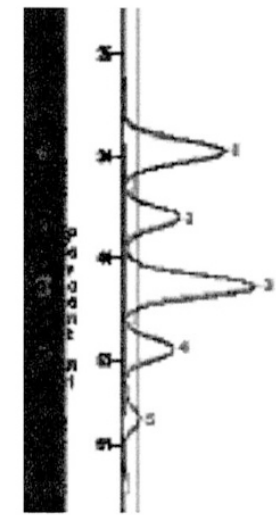

$\mathbf{N}$

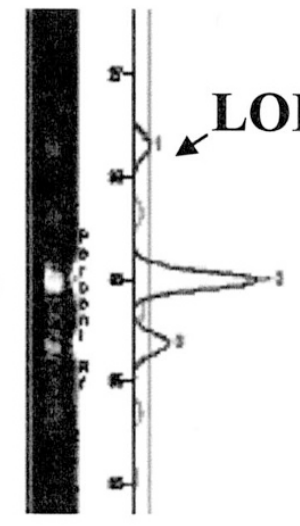

$\mathrm{T}$
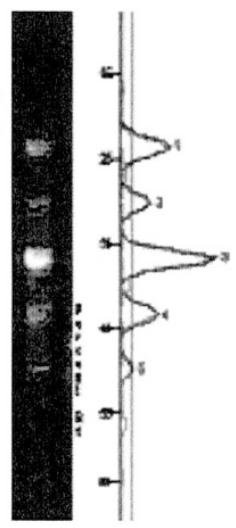

$\mathbf{N}$

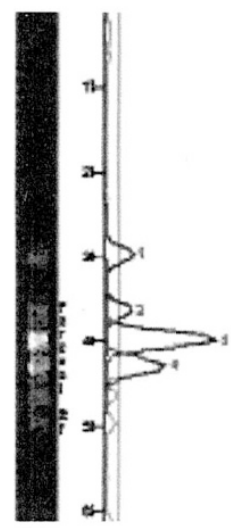

$\mathrm{T}$

NORMAL

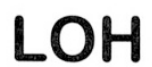

MIN

FIGURE 2. A, ideogram of chromosomes 13 and 17 showing the localization of 10 polymorphic markers used for microsatellite analysis. The chromosome ideograms were courtesy of the University of Bari, Italy (www.biologia.uniba.it/rmc/0-internal-images/z-ideograms/ideograms.html). Distance between markers is indicated in Centimorgans (22). B, genetic alterations seen in microsatellite analysis. The left panel (normal) shows two peaks representing the two alleles of an informative locus, $\mathrm{N}$ from normal tissue and $\mathrm{T}$ from cancer tissue of the same individual; the middle panel shows an example of loss of heterozygosity where it shows the presence of two alleles in normal tissue (N) and loss of one allele in tumor tissue ( $\mathrm{T}$ ); and the right panel shows an example of microsatellite instability (MIN) with two alleles in normal tissue (N), but in cancer tissue (T) the alleles have altered molecular weight, smaller in this example as compared with the alleles of its corresponding normal tissue.

Genomic Resource, England (http://www.hgmp. mrc.ac.uk) after high-stringency hybridization screening of a human PAC library. The $R B 1$ probe was a $37 \mathrm{~Kb}$ cosmid that contained microsatellite markers RBi2, RBi4, RBi17, and RBi21 by PCR analysis. The $p 53$ probe was a PAC (89K1) confirmed by PCR and sequencing to contain a known 330-bp p53 genomic sequence (14438-14768 from
HSU94788). An alphoid centromeric probe for chromosome 17 was obtained from Resources for Molecular Genetics, Italy (http://www.biologia.uniba.it) and confirmed by FISH localization in lymphocyte metaphase spreads.

Nuclei for FISH were either prepared by touches from fresh-frozen tumor samples when available (25), or by laser capture microdissection of pure 
cancer nuclei from paraffin sections (26). FISH was performed according to our established methods (27). Briefly, column-purified (Qiagen) cosmid or BAC probes were labeled by nick translation with digoxigenin or FITC-dUTP. After denaturation in $70 \%$ formamide at $80^{\circ} \mathrm{C}$, they were hybridized to the samples overnight in a solution containing human Cot DNA, $50 \%$ formamide, $10 \%$ dextran sulfate, and $2 \times$ SSC followed by initial washes in $50 \%$ formamide $/ 2 \times \mathrm{SSC}$ at $42^{\circ} \mathrm{C}$ and additional washes in $1 \times$ SSC. Signals were detected by incubating the slides with primary antibody solution (1:100 donkey anti digoxigenin or rabbit anti-FITC), followed by incubation with secondary antibody containing 1:50 Cy3 sheep-anti donkey (Jackson Immunoresearch) or FITC goat anti-rabbit. The slides were counterstained with 4,6-diamidino-2-phenylindole (DAPI, $40 \mathrm{pg} / \mathrm{mL}$ ) for $5 \mathrm{~min}$ to highlight nuclei. A total of 25-30 nuclei were analyzed for each sample using a fluorescence microscope, where 2-4 signals were expected. If a significant number of 1-2 signal nuclei were observed $(>10 \%)$, possibly indicating a gene deletion, more nuclei were evaluated. If $<10 \%$ nuclei showed only 1 signal (presumably because of less than perfect staining efficiency), the sample was judged to have a normal copy number.

\section{RESULTS}

Table 1 shows the frequency of loss of heterozygosity observed in 50 breast cancer-normal tissue pairs examined for 10 dinucleotide polymorphic markers within and around the two tumor suppressor genes, p53 and RB1 (Fig. 2A). Twenty-five of 50 (50\%) breast cancer cases showed loss of heterozygosity for $\geq 1$ of the 10 polymorphic markers at the two locations analyzed. Figure $2 \mathrm{~B}$ shows examples of genetic alteration observed by microsatellite analysis of our breast cancer specimens. These abnormalities include loss of heterozygosity, where one of the alleles is lost in the tumor sample as compared with its heterozygous control, and mic-

TABLE 1. Frequency of Loss of Heterozygosity Analyzed for 10 Polymorphic Markers on Chromosomes 13 and 17 in 50 Breast Tumor Specimens

\begin{tabular}{lcccc}
\hline Marker & $\begin{array}{c}\text { Tumors with Loss of } \\
\text { Heterozygosity }\end{array}$ & $\begin{array}{c}\text { Informative } \\
\text { Tumors }\end{array}$ & $\begin{array}{c}\text { Tumors } \\
\text { Analyzed }\end{array}$ & $\begin{array}{c}\text { \% Loss of } \\
\text { Heterozygosity of } \\
\text { Informative Alleles }\end{array}$ \\
\hline D13S260 & 3 & 38 & 47 & 7.8 \\
D13S270 & 3 & 38 & 50 & 7.8 \\
Rbi2 & 4 & 48 & 50 & 8.3 \\
D13S172 & 7 & 45 & 49 & 15.5 \\
D13S274 & 1 & 39 & 50 & 2.5 \\
D17S938 & 6 & 39 & 45 & 15.3 \\
D17S796 & 4 & 46 & 48 & 8.6 \\
P53 15.1 & 7 & 43 & 48 & 16 \\
D17S786 & 1 & 40 & 48 & 2.5 \\
D17S795 & 0 & 49 & 50 & 0 \\
Total & 36 & 425 & 485 & 8.5 \\
\hline
\end{tabular}

rosatellite instability, where the tumor shows alleles of different size, as compared with its corresponding control. Although allelic gain cannot be ruled out, it is thought to be unlikely in the context of a tumor suppressor gene locus. Out of the total of 425 informative loci examined, 36 (8.5\%) showed loss of heterozygosity. Figure 3 shows the distribution of different genetic alterations seen for 10 informative polymorphic markers (yellow and red) on chromosome 13 and 17 in the 50 breast cancer samples. Markers D13S172 (5 cM apart from RBi2) and RBi2 (intron 2 in $R B 1$ gene) on chromosome 13 showed occurrence of loss of heterozygosity with a frequency of $15.5 \%$ and $8.3 \%$ respectively. Case 30 was at least tetraploid for chromosome 17 (four to six centromeric signals), though with deletion of $p 53$ (only two signals instead of four, Fig. 4D). Microsatellite analysis of the same case showed loss of heterozygosity of the p53 marker but was normal for other markers on chromosome 17. Case 40 was

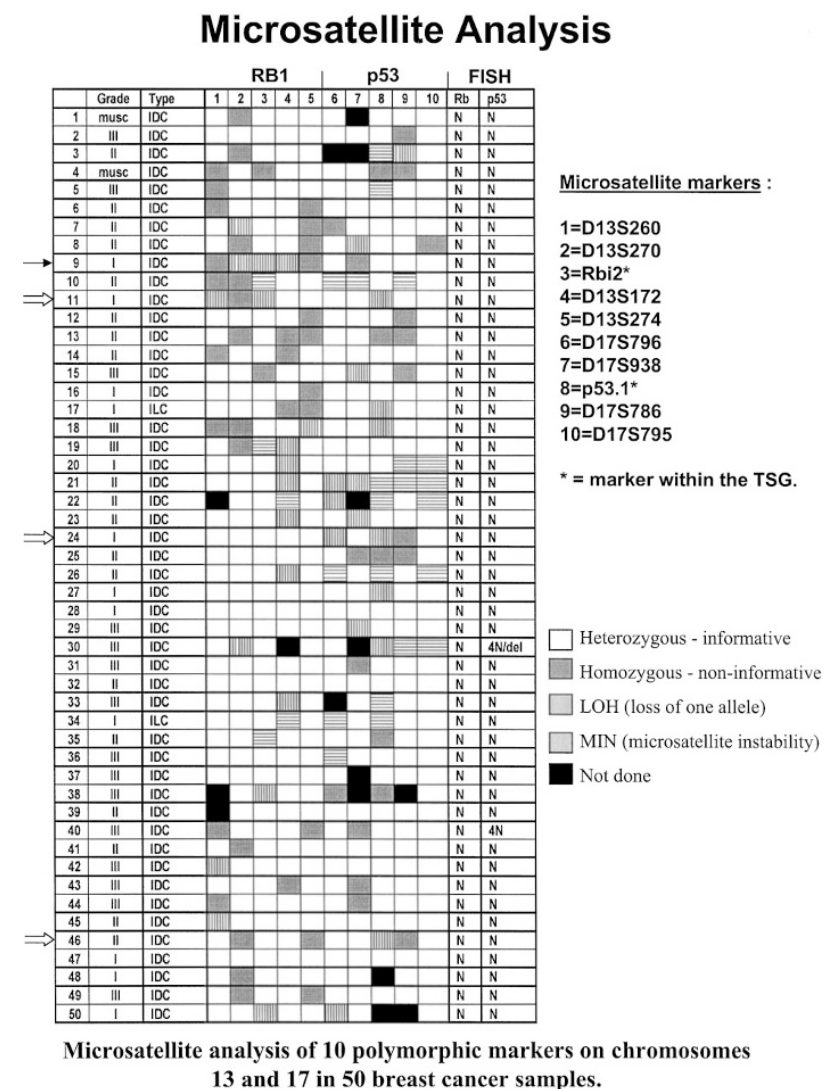

FIGURE 3. Results of microsatellite analysis of 10 polymorphic markers on chromosome 13 and 17 from 50 tumor samples. Legend indicates result of analysis. Case 9 (solid arrow) shows loss of heterozygosity for three markers within and spanning RB1. Cases 11, 24 , and 46 (open arrows) show loss of heterozygosity within the tumor suppressor gene as well as for at least one marker spanning the tumor suppressor gene (informative or un-informative). The last two columns show data of FISH copy analysis for the tumor suppressor genes $R B 1$ and $p 53 . N=$ normal copy number with $2-4$ signals. Case 30 is tetraploid for chromosome 17 with 4 signals $(4 \mathrm{~N})$ and deletion (del) of p53 with only 2 signals. Case 40 is tetraploid with 4 centromeric signals and 4 signals for p53 $(4 \mathrm{~N})$. 

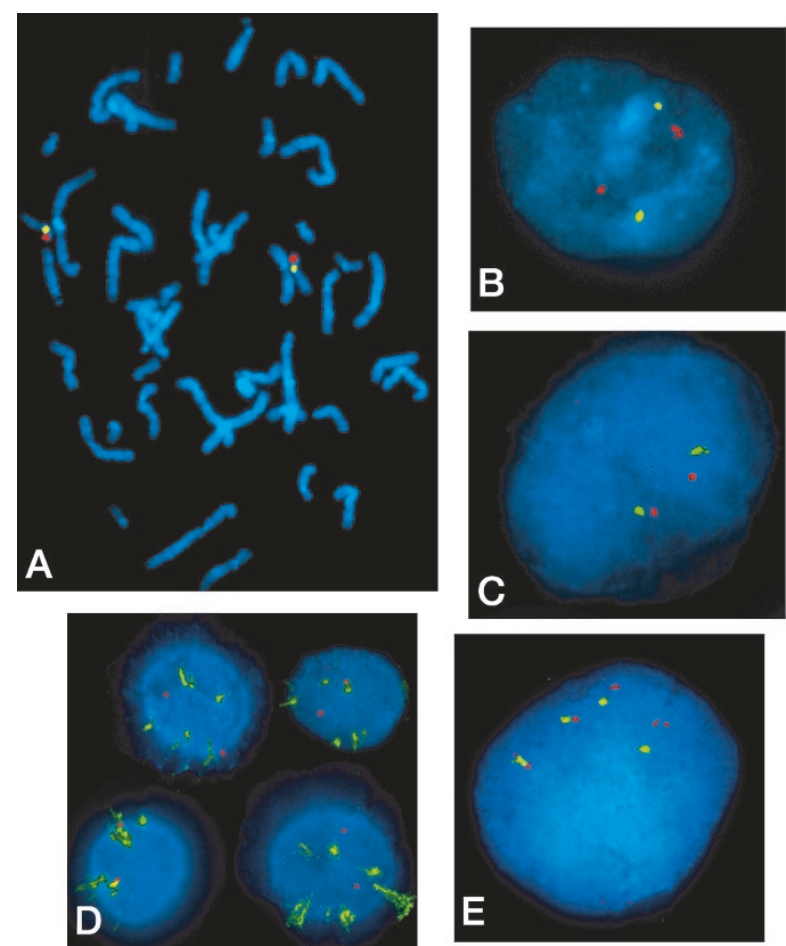

FIGURE 4. FISH analysis showing chromosomal localization of p53 using a genomic p53 PAC probe and chromosome 17 centromere using a 17 centromeric $\propto$-satellite probe. Normal gene copy numbers are shown in a control metaphase (A), an interphase from normal lymphocytes (B), and an interphase from a breast tumor sample (C). Staining for the $p 53$ probe shows two red signals and the 17 centromeric $\propto$-satellite probe shows two green signals. Case 30 (D) showing at least tetraploidy for chromosome 17 (4+ centromeric signals) and deletion of p53 (only two signals) and Case 40 (E) showing tetraploidy for chromosome 17 as well as for p53 (4 signals).

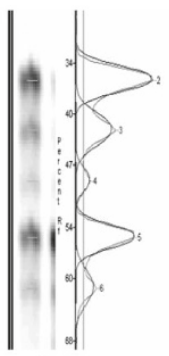

$\mathbf{N}$

A

D13S172

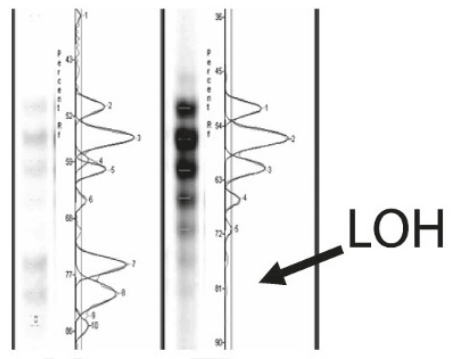

N T

RBi2

B

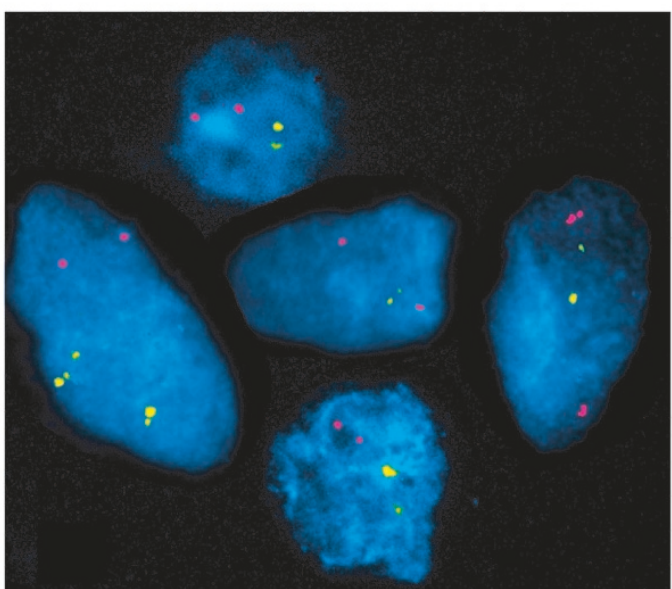

FIGURE 5. Microsatellite and FISH analysis of Case 9. Polymorphic markers RBi2 and D13S172 located 5 cM apart both showing loss of heterozygosity including the $R B 1$ locus in Case 9 (A). FISH analysis of the same tumor sample with probes for $R B 1$ (red) and p53 (green) showing normal gene copy number for the two genes (B). 
tetraploid for chromosome 17 as well as for the $p 53$ gene (Fig. 4E), and no loss of heterozygosity for any marker on chromosome 17 was found. As observed in Case 9, the three polymorphic markers, D13S270, RBi2, and D13S172 (within $6 \mathrm{cM}$ ) demonstrated loss of heterozygosity (Fig. 5A), whereas FISH analysis of the same case showed normal copy number signals for the $R B 1$ gene (Fig. 5B). Of the 5 polymorphic markers analyzed on chromosome 17, markers p53.1 (within the p53 gene) and D17S938 (1.5 cM apart from p53.1) showed loss of heterozygosity most frequently ( $16.0 \%$ and $15.3 \%$ respectively). Cases 11, 24, and 46 show loss of heterozygosity of tumor suppressor gene-spanning markers or are noninformative. FISH analysis of these cases showed the presence of two normal signals for $p 53$ and $R B 1$. At least three of four cases $(11,24$, and 46$)$ are candidates for uniparental disomy, likely due to somatic recombination versus mitotic nondisjunction, as distal markers retained heterozygosity (Fig. 3). Chromosomal isodisomy cannot be ruled out for case 9 . As well, 7 of 50 cases showed MIN, as characterized by microsatellite instability at more than one locus, and two of these showed multiallele loss of heterozygosity (Cases 21 and 22).

In summary, our data shows 4 cases of 50 in which there is a discordance between loss of heterozygosity of markers spanning or within a tumor suppressor gene, and copy number of the tumor suppressor gene. These 4 cases were from breast carcinomas that demonstrated a low or intermediate grade versus a high grade. Microsatellite instability was also observed, sometimes in the context of loss of heterozygosity, but did not appear to correlate with tumor grade.

\section{DISCUSSION}

Our study finds that specific cases of breast carcinoma, showing loss of heterozygosity for polymorphic markers in and around two known tumor suppressor genes, may still retain two copies of the tumor suppressor gene, which suggests a recombination event yielding two isoparental alleles rather than a simple deletion-uniparental disomy. Microdeletion of the specific marker, which may still result in normal FISH signal with the genomic probe, could not be ruled out in our study or other comparable studies. Only genomic sequencing of the specimens could completely rule out this possibility. The relatively small size of our genomic FISH probes suggests that this explanation is unlikely, as well as the occurrence of multiple or genespanning loss of heterozygosity in Cases 9, 11, and 24 . We find a prevalence of approximately $8 \%$ of uniparental disomy in our breast cancer cases around either $R B 1$ and $p 53$ loci. Examination of the four cases suggesting a nondeletional mechanism for loss of heterozygosity suggested an association with low-grade cancers more than with high grade cancer, though this would be better evaluated with a larger sample size. Although our $R B 1$ results are compatible with other studies, our $p 53$ results are in contrast to one previous report (18). The difference between our study and the other may lie in the case selection. In our study we deliberately included many low-grade cases. It is possible that the previous study used higher grade cases, as this was not clearly documented. Higher grade has been shown to correlate with greater degrees of aneuploidy and likely deletions (28-30). Less likely, the p53 BAC probe that we used could have covered up microdeletions that would have been detected with the multiple smaller probes used in the previous study (18). A previous study using a PCR-based microdeletion assay did not find physical deletions of $p 53$ in any of 19 breast carcinomas (31); however, another study of 23 formalin-fixed paraffin-embedded breast carcinomas did report frequent physical deletions of $p 53$ (32), suggesting that tumor sample selection is likely important. Interestingly, p53 is one of the rare tumor suppressor genes that displays a dominant-negative phenotype (33), suggesting that a nondeletional mechanism of inactivation would be more likely selected.

In any given malignancy, frequent loss of heterozygosity (loss of heterozygosity) involving a discrete chromosomal region is generally considered an indication of the presence of a tumor suppressor gene, whose loss/inactivation contributes to the development or progression of that tumor. Detailed loss-of-heterozygosity analysis of polymorphic loci distributed along a chromosome can reveal a common minimal region of "deletion" in which a putative tumor suppressor gene may reside. This has usually been demonstrated in tumor tissues or cell lines by loss of heterozygosity studies using polymorphic markers around the tumor suppressor gene $(10,34-36)$. By interpretation of Knudson's hypothesis, inactivation of a tumor suppressor gene follows either inheritance or occurrence of a spontaneous tumor suppressor gene mutation, with subsequent loss of the other wild type allele. It has been suggested that this second hit for tumor suppressor gene inactivation can occur by several ways (see Fig. 1): non-disjunction (2a), deletion (2c), recombination (2d), and/or chromosome loss (2b) with or without duplication (3b, 3c, 3d; 3, 10, 12, 37, 38). Some of these can lead to uniparental disomy, with two copies of a tumor suppressor gene, rather than deletion which leaves one copy. Uniparental disomy can occur as heterodisomy, whereby sequences from both homologues of the transmitting parent are present $(2 \mathrm{~d}, 3 \mathrm{c}, 3 \mathrm{~d})$, or as isodisomy (3a, $3 b)$, in which two identical segments from one par- 
ent homologue are present (12). A consequence of either mechanism is that it may allow two copies of a recessive mutation to be transmitted from a heterozygous carrier parent (39). Mitotic nondisjunction events resulting in chromosome replacement, that is, loss of one chromosome followed by duplication of the other chromosome with retention of gene number, may contribute to some cases of loss of heterozygosity and usually are associated with pediatric inherited cancers such as retinoblastoma and Wilms' tumor (5, 14-16, 39-42). Somatic recombination leading to uniparental disomy, however, is also an important mechanism leading to loss of heterozygosity or loss of imprinting, also associated with inherited cancers like retinoblastoma (10) or Wilms' tumor $(14,20,43)$, and skin cancers (44). Loss of constitutional heterozygosity resulting in homozygosity or hemizygosity for region 11 p15 has also been observed in tumors of some types in Beckwith-Wiedemann syndrome (14). Investigation of uveal melanomas (45) have revealed loss of heterozygosity in pigmented tumors with monosomy of chromosome 3 , as well as in nonpigmented tumors with two copies of chromosome 3 , indicating the occurrence of chromosome loss and/or duplication during the clonal evolution of the tumor. Non-cancer-associated uniparental disomy has also been identified through homozygosity of recessive mutation as shown in cases of cystic fibrosis, hemophilia A and other genetic conditions (46).

The results of FISH and microsatellite analysis in the present study show loss of heterozygosity of at least one sampled locus in $50 \%$ of the tumor specimens. The presence of two copies of tumor suppressor gene by FISH, particularly in Case 9 and potentially Cases 11, 24 and 46, with loss of heterozygosity within and spanning tumor suppressor gene markers involving large molecular distances, indicate that loss of heterozygosity in some of our specimens is not due to deletion only but may be due to loss followed by duplication of the remaining allele or due to a recombinational event.

Our study shows evidence for uniparental disomy as a potential mechanism for some cases of observed loss of heterozygosity found at two different tumor suppressor loci in adult spontaneous breast cancers. In a rapidly growing tumor, uniparental disomy may result in two copies of an abnormal allele in a subclone, which may be selected as the dominant clone in tumor outgrowth. Further evidence for this model would be provided by a detailed sequence analysis of the candidate tumor suppressor gene within the genomic region, which would be expected to identify a homozygous inactivating mutation, but such efforts are well beyond the limits of this study. Although $R B 1$ and $p 53$ genomic regions are often noted to be involved in loss of heterozygosity regions in breast cancer, the prevalence is not as high as in other tumors, and the potential for selection of a dominant-negative mutant of $p 53$ in the context of a normal allele is a complicating factor. Consequently, other tumor systems and tumor suppressor genes would be helpful to establish whether uniparental disomy is a pervasive mechanism for tumor suppressor gene inactivation. Other work has identified uniparental disomy in breast cancer $(17,19)$ and astrocytomas (13) associated with loss of heterozygosity, in addition to the inherited pediatric cancers discussed previously. A recent publication has discussed the mechanism of tumor suppressor gene inactivation after a very thorough analysis of colon cancer (9). This group studied 5 chromosomes in which tumor suppressor genes were known to localize. The study showed a high frequency of loss of heterozygosity for all of the chromosomes, but chromosomespecific mechanisms to account for the loss of heterozygosity. Some examples of the loss of heterozygosity were mediated by either complete or partial chromosome loss, whereas other examples were mediated by mitotic nondisjunction with chromosome duplication. Interestingly, somatic recombination resulting in uniparental disomy was not observed by these investigators in their colon cancer specimens, in contrast to studies by us and others, evaluating breast or other cancers. The investigators suggest that their observations in colon carcinoma likely apply to other tumors and that microdeletions may explain observations of somatic recombination (9). An alternate explanation could be that tumor and/or tumor suppressor gene-specific mechanisms select for either deletion or somatic recombination modes of loss of heterozygosity, due to either tumor-specific genomic dysregulation or chromosomal geography. For example, the physical proximity of two tumor suppressor genes may select for deletions, resulting in the loss of both. This situation is illustrated by the tumor suppressor gene, $p 16^{I N K 4 a}$, which is known to demonstrate a very high incidence of homozygous deletion in diverse tumors (47-49). This unusually high prevalence of homozygous deletion may be explained by the partial encoding of another tumor suppressor gene, $p 14^{A R F}$, and its physical proximity to the related tumor suppressor gene, $p 15^{I N K 4 b}(50)$. The converse is illustrated by the case in which a tumor suppressor gene is in proximity to a protooncogene. In this scenario, although a microdeletion resulting in specific loss of the tumor suppressor gene may be potentially selected, several such events may need to occur before the generation of an appropriate clone with loss of the tumor suppressor gene locus but retention of the protooncogene locus. By contrast, any example of somatic recombination resulting in exchange of an 
inactive for an active tumor suppressor gene allele would result in an appropriate genotype for clonal selection. Such a hypothesis may explain why different modes of loss of heterozygosity can be observed by the same investigators in different chromosomal loci of the same specimen pool (19). Of course, this model is speculative but testable.

Further studies of the mechanism of loss of heterozygosity are important because dysfunctional cellular processes that could yield either a structural deletion or a somatic recombination event could define distinct cellular pathways. Dysfunction of such specific pathways could identify either a novel therapeutic target or a predictive marker for the response of a cancer to an existing therapy such as DNA active agents or radiotherapy.

Acknowledgments: Equipment used in this project was established by the Alberta Science and Research Authority and the Canadian Foundation for Innovation, and this project also utilized the services of the Alberta Cancer Board Histology Center. The Canadian Institutes of Health Research and Calgary Laboratory Services provided access to clinical material through the CLS Tumor Tissue Repository.

\section{REFERENCES}

1. Weinberg RA. Tumor suppressor genes. Science 1991;254: $1138-46$.

2. Yokota J, Sugimura T. Multiple steps in carcinogenesis involving alterations of multiple tumor suppressor genes. FASEB J 1993;7:920-5.

3. Knudson AG Jr. Mutation and cancer: statistical study of retinoblastoma. Proc Natl Acad Sci U S A 1971;68:820-3.

4. Knudson AG Jr. Genetics of human cancer. J Cell Physiol Suppl 1986;4:7-11.

5. Knudson AG Jr. Pediatric molecular oncology. Past as prologue to the future. Cancer 1993;71(10 Suppl):3320-4.

6. Stanbridge EJ. Human tumor suppressor genes. Annu Rev Genet 1990;24:615-57.

7. Yandell DW, Campbell TA, Dayton SH, Petersen R, Walton D, Little JB, et al. Oncogenic point mutations in the human retinoblastoma gene: their application to genetic counseling. N Engl J Med 1989;321:1689-95.

8. Dunn JM, Phillips RA, Zhu X, Becker A, Gallie BL. Mutations in the RB1 gene and their effects on transcription. Mol Cell Biol 1989;9:4596-604.

9. Thiagalingam S, Laken S, Willson JK, Markowitz SD, Kinzler KW, Vogelstein B, et al. Mechanisms underlying losses of heterozygosity in human colorectal cancers. Proc Natl Acad Sci U S A 2001;98:2698-702.

10. Zhu X, Dunn JM, Goddard AD, Squire JA, Becker A, Phillips RA, et al. Mechanisms of loss of heterozygosity in retinoblastoma. Cytogenet Cell Genet 1992;59:248-52.

11. de Nooij-van Dalen AG, van Buuren-van Seggelen VH, Lohman PH, Giphart-Gassler M. Chromosome loss with concomitant duplication and recombination both contribute most to loss of heterozygosity in vitro. Genes Chromosomes Cancer 1998;21:30-8.

12. Robinson WP. Mechanisms leading to uniparental disomy and their clinical consequences. Bioessays 2000;22:452-9.
13. Cavenee WK, Dryja TP, Phillips RA, Benedict WF, Godbout R, Gallie BL, et al. Expression of recessive alleles by chromosomal mechanisms in retinoblastoma. Nature 1983;305:77984.

14. Henry I, Puech A, Riesewijk A, Ahnine L, Mannens M, Beldjord C, et al. Somatic mosaicism for partial paternal isodisomy in Wiedemann-Beckwith syndrome: a post-fertilization event. Eur J Hum Genet 1993;1:19-29.

15. Grundy P, Wilson B, Telzerow P, Zhou W, Paterson MC. Uniparental disomy occurs infrequently in Wilms tumor patients. Am J Hum Genet 1994;54:282-9.

16. Henry I, Bonaiti-Pellie C, Chehensse V, Beldjord C, Schwartz C, Utermann G, et al. Uniparental paternal disomy in a genetic cancer-predisposing syndrome. Nature 1991;351:665-7.

17. Kallioniemi A, Kallioniemi OP, Waldman FM, Chen LC, Yu LC, Fung YK, et al. Detection of retinoblastoma gene copy number in metaphase chromosomes and interphase nuclei by fluorescence in situ hybridization. Cytogenet Cell Genet 1992;60:190-3.

18. Matsumura K, Kallioniemi A, Kallioniemi O, Chen L, Smith HS, Pinkel D, et al. Deletion of chromosome 17p loci in breast cancer cells detected by fluorescence in situ hybridization. Cancer Res 1992;52:3474-7.

19. Chen LC, Matsumura K, Deng G, Kurisu W, Ljung BM, Lerman MI, et al. Deletion of two separate regions on chromosome 3p in breast cancers. Cancer Res 1994;54:3021-4.

20. Shearer PD, Valentine MB, Grundy P, DeCou JM, Banavali $\mathrm{SD}$, Komuro $\mathrm{H}$, et al. Hemizygous deletions of chromosome band 16q24 in Wilms tumor: detection by fluorescence in situ hybridization. Cancer Genet Cytogenet 1999;115:100-5.

21. Emmert-Buck MR, Bonner RF, Smith PD, Chuaqui RF, Zhuang Z, Goldstein SR, et al. Laser capture microdissection. Science 1996;274:998-1001.

22. Gyapay G, Morissette J, Vignal A, Dib C, Fizames C, Millasseau $\mathrm{P}$, et al. The.-94 Genethon human genetic linkage map. Nat Genet 1994;1993:7(2 Spec No):246-339.

23. Tsukamoto K, Ito N, Yoshimoto M, Iwase T, Tada T, Kasumi $\mathrm{F}$, et al. Two distinct commonly deleted regions on chromosome 13q suggest involvement of BRCA2 and retinoblastoma genes in sporadic breast carcinomas. Cancer 1996;78:192934.

24. Boland CR, Thibodeau SN, Hamilton SR, Sidransky D, Eshleman JR, Burt RW, et al. A National Cancer Institute Workshop on Microsatellite Instability for cancer detection and familial predisposition: development of international criteria for the determination of microsatellite instability in colorectal cancer. Cancer Res 1998;58:5248-57.

25. Demetrick D. The use of archival frozen tumour tissue specimens for fluorescence in situ hybridization. Mod Pathol 1996;9:133-6.

26. DiFrancesco LM, Murthy SK, Luider J, Demetrick DJ. Laser capture microdissection-guided fluorescence in situ hybridization and flow cytometric cell cycle analysis of purified nuclei from paraffin sections. Mod Pathol 2000;13:705-11.

27. Demetrick DJ. Fluorescence in situ hybridization and human cell cycle genes. In: Pagano M, editor. Cell cycle: materials and methods. 1st ed. Zurich, Switzerland: Springer Verlag Press; 1995. p. 29-45.

28. Smith FB, Zappi ME. Relationships between image cytometric DNA index, proliferation fraction and multiploidy and conventional nuclear grade in breast carcinoma. Mod Pathol 1993;6:606-11.

29. Ioakim-Liossi A, Karakitsos P, Aroni K, Markopoulos C, Delivelioti K, Gogas J, et al. DNA ploidy and pS2 protein expression in breast cancer. Cytopathology 1997;8:171-6.

30. Wong SW, Rangan AM, Bilous AM, Boyages J, Gebski V, Benson EM. The value of S-phase and DNA ploidy analysis as prognostic markers for node-negative breast cancer in the Australian setting. Pathology 1999;31:90-4. 
31. Angelopoulou K, Diamandis EP. Identification of deletions and insertions in the p53 gene using multiplex PCR and high-resolution fragment analysis: application to breast and ovarian tumors. J Clin Lab Anal 1998;12:250-6.

32. Eyfjord JE, Thorlacius S, Steinarsdottir M, Valgardsdottir R, Ogmundsdottir HM, Anamthawat-Jonsson K. p53 abnormalities and genomic instability in primary human breast carcinomas. Cancer Res 1995;55:646-51.

33. Monti P, Campomenosi P, Ciribilli Y, Iannone R, Inga A, Abbondandolo A, et al. Tumour p53 mutations exhibit promoter selective dominance over wild type p53. Oncogene 2002;21:1641-8.

34. Boige V, Laurent-Puig P, Fouchet P, Flejou JF, Monges G, Bedossa $\mathrm{P}$, et al. Concerted nonsyntenic allelic losses in hyperploid hepatocellular carcinoma as determined by a high-resolution allelotype. Cancer Res 1997;57:1986-90.

35. Kerangueven F, Noguchi T, Coulier F, Allione F, Wargniez V, Simony-Lafontaine J, et al. Genome-wide search for loss of heterozygosity shows extensive genetic diversity of human breast carcinomas. Cancer Res 1997;57:5469-74.

36. Kerangueven F, Eisinger F, Noguchi T, Allione F, Wargniez V, Eng C, et al. Loss of heterozygosity in human breast carcinomas in the ataxia telangiectasia, Cowden disease and BRCAl gene regions. Oncogene 1997;14:339-47.

37. Klinedinst DK, Drinkwater NR. Reduction to homozygosity is the predominant spontaneous mutational event in cultured human lymphoblastoid cells. Mutat Res 1991;250:365-74.

38. Dalen DNV. Chromosome loss with concomitant duplication and recombination both contribute most to loss of heterozygosity in vitro. Genes Chromosomes Cancer 1998; 21:30-8.

39. Engel E. A new genetic concept: uniparental disomy and its potential effect, isodisomy. Am J Med Genet 1980;6:137-43.

40. Dutly F, Baumer A, Kayserili H, Yuksel-Apak M, Zerova T, Hebisch G, et al. Seven cases of Wiedmann-Beckwith syndrome, including the first reported case of mosaic paternal isodisomy along the whole chromosome 11. Am J Med Genet 1998;79:347-53.

41. Chao LY, Huff V, Tomlinson G, Riccardi VM, Strong LC, Saunders GF. Genetic mosaicism in normal tissues of Wilms' tumour patients. Nat Genet 1993;3:127-31.

42. Dutly F, Balmer D, Baumer A, Binkert F, Schinzel A. Isochromosomes $12 p$ and 9p: parental origin and possible mechanisms of formation. Eur J Hum Genet 1998;6:140-4.

43. Henry I, Bonaiti-Pellie C, Chehensse V, Beldjord C, Schwartz C, Utermann G, et al. Uniparental paternal disomy in a genetic cancer-predisposing syndrome. Nature 1991;351:665-7.

44. Happle R. Loss of heterozygosity in human skin. J Am Acad Dermatol 1999;41(2 Pt 1):143-64.

45. White VA, McNeil BK, Thiberville L, Horsman DE. Acquired homozygosity (isodisomy) of chromosome 3 during clonal evolution of a uveal melanoma: association with morphologic heterogeneity. Genes Chromosomes Cancer 1996;15: $138-43$.

46. Engel E. Uniparental disomies in unselected populations. Am J Hum Genet 1998;63:962-6.

47. Hebert J, Cayuela JM, Berkeley J, Sigaux F. Candidate tumorsuppressor genes MTS1 (p16INK4A) and MTS2 (p15INK4B) display frequent homozygous deletions in primary cells from T- but not from B-cell lineage acute lymphoblastic leukemias. Blood 1994;84:4038-44.

48. Jen J, Harper JW, Bigner SH, Bigner DD, Papadopoulos N, Markowitz S, et al. Deletion of p16 and p15 genes in brain tumors. Cancer Res 1994;54:6353-8.

49. Okamoto A, Demetrick DJ, Spillare EA, Hagiwara K, Hussain SP, Bennett WP, et al. Mutations and altered expression of p16INK4 in human cancer. Proc Natl Acad Sci U S A 1994; 91:11045-9.

50. Sherr CJ. The INK4a/ARF network in tumour suppression. Nat Rev Mol Cell Biol 2001;2:731-7. 